OPEN ACCESS

Edited by:

Anthony Griffiths,

Boston University, United States

Reviewed by:

Igor Jurak

University of Rijeka, Croatia

Nicoletta Potenza

Università degli Studi della Campania

"Luigi Vanvitelli", Italy

*Correspondence:

Jie Peng

piie138@163.com

Specialty section:

This article was submitted to

$R N A$,

a section of the journal

Frontiers in Genetics

Received: 26 October 2018

Accepted: 04 March 2019

Published: 22 March 2019

Citation:

Wu Y, Gao C, Cai S, Xia M, Liao G, Zhang X and Peng J (2019) Circulating miR-122 Is a Predictor for Virological Response in CHB Patients With High Viral Load Treated With

Nucleos(t)ide Analogs.

Front. Genet. 10:243.

doi: 10.3389/fgene.2019.00243

\section{Circulating miR-122 Is a Predictor for Virological Response in CHB Patients With High Viral Load Treated With Nucleos(t)ide Analogs}

\author{
Yin Wu${ }^{1}$, Chang Gao ${ }^{1}$, Shaohang Cai ${ }^{2}$, Muye Xia ${ }^{1}$, Guichan Liao ${ }^{1}$, Xiaoyong Zhang ${ }^{1}$ and \\ Jie Peng ${ }^{1 *}$
}

' State Key Laboratory of Organ Failure Research, Guangdong Provincial Key Laboratory of Viral Hepatitis Research, Department of Infectious Diseases, Nanfang Hospital, Southern Medical University, Guangzhou, China, ${ }^{2}$ Department of Pathology, Sun Yat-sen University Cancer Center, Guangzhou, China

Chronic hepatitis B $(\mathrm{CHB})$ infection remains worldwide health problem. Antiviral treatment options for CHB patients include nucleos(t)ide analogs (NAs) and interferon. Most of the current biomarkers for predicting treatment response are virus-dependent. MicroRNA-122 is the most abundant liver-specific miRNA and has been identified involved in multiple liver physiology and pathology including hepatotropic virus infection. To identify the role of miR-122 in NA therapy, $80 \mathrm{CHB}$ patients with high viral load (HVL) were enrolled and serum miR-122 levels at baseline, week 12 and week 24 were measured. Serum miR-122 levels were significantly lower in patients who developed virological response (VR), compared with non-VR group. Levels of miR-122 at week 12 and week 24 were determined to be independent prognostic indicators for a VR with satisfactory AUROC values at 0.812 and 0.800 , respectively. During NA therapy, serum miR-122 level deceased steadily and an earlier reduction was observed in VR group, indicating early reduction of miR-122 level might increase the possibility of developing virological response. In conclusion, we identified the dynamic change of serum miR-122 level and miR-122 levels at week 12 and week 24 as independent predictors for VR in CHB patients with HVL treated with NAs.

Keywords: microRNA-122, chronic hepatitis B, virological response, high viral load, nucleos(t)ide analogs

\section{INTRODUCTION}

Over 240 million people worldwide are living with chronic hepatitis B virus (HBV) infection, and China is one of the countries with the highest population of HBsAg-positive individuals (Schweitzer et al., 2015). Chronic HBV infection can lead to fatal complications including liver cirrhosis, liver failure, and hepatocellular carcinoma (HCC), resulted from repeated flares and continuous inflammation (Chang and Lewin, 2007).

The clinical outcome of infection depends on a complex interaction between viral factors and host immune response (Dandri and Locarnini, 2012). Currently, antiviral treatment options for chronic hepatitis $\mathrm{B}(\mathrm{CHB})$ patients include nucleos $(\mathrm{t})$ ide analogs (NAs) and interferon (Lampertico et al., 2017). Previous studies have identified several predictors for treatment response to NA 
therapy, such as alanine aminotransferase (ALT) (Perrillo et al., 2002; Wong et al., 2018), interferon-inducible protein 10 (Jaroszewicz et al., 2011; Wong et al., 2016), hepatitis B surface antigen (Jaroszewicz et al., 2011; Chen et al., 2014; Wang et al., 2014) and hepatitis B core antibody levels (Fan et al., 2016; Cai et al., 2018). Yet, most of these predictors are virus-dependent, moreover, only a handful are performed in $\mathrm{CHB}$ patients with high viral load (HVL) at baseline.

MicroRNAs (miRNAs) are a large class of small non-coding RNAs that post-transcriptionally regulate one third of human genes. These approximately 22-nucleotides long RNAs play important roles in physiological processes as well as occurrence and development of human diseases. Likewise, they exhibit the potential as disease biomarkers and therapeutic targets (Hammond, 2015). MiRNAs, one of the host factors influencing virus-host interactions, play an important role on regulation of HBV replication and host cell metabolism (Deng and Lu, 2016). A large quantity of miRNAs are involved in control of $\mathrm{HBV}$ replication. For instance, miR-26b was identified to decrease HBV enhancer/promoter activities and inhibit viral transcription (Zhao et al., 2014), miR-199a-3p and miR-210 show the ability to reduce HBsAg expression (Zhang et al., 2010), miR-125a$5 p$ interferes with the viral sequence (Potenza et al., 2011) and miR-204 was found to target HBV mRNAs (Huang et al., 2016).

In mammals, miR-122 is the most abundant liver-specific miRNA, almost undetectable in other tissues (Lagos-Quintana et al., 2002; Landgraf et al., 2007), and involved in multiple liver physiology and pathology including liver development, lipid metabolism, hepatotropic virus infection and development of $\mathrm{HCC}$ ( $\mathrm{Hu}$ et al., 2012). In vitro studies have reported that downregulation of endogenous miR-122 enhanced HBV replication, whereas upregulated miR-122 led to suppression of HBV (Wang et al., 2012). Furthermore, circulating miR-122 in CHB patients was identified to positively correlate with ALT and HBV DNA levels (Waidmann et al., 2012; Xing et al., 2014; Akamatsu et al., 2015), implying that circulating miR-122 levels have the potential to reflect liver damage and the magnitude of viral infection, and might further indicate the outcomes of antiviral therapy.

The aim of this study was to identify the role of serum miR122 levels as predictors for treatment response in CHB patients with pre-treatment HVL treated with NAs. Secondary, we aim to explore the dynamic changes of miR-122 during NA treatment.

\section{MATERIALS AND METHODS}

\section{Study Subjects}

This study was comprised of $80 \mathrm{CHB}$ patients with HVL (HBV DNA $>10^{7}$ copies $/ \mathrm{mL}$ ) at baseline, enrolled in a prospective, multicenter, controlled trial, treated with lamivudine (LAM) and adefovir (ADV) $(n=38)$ or entecavir (ETV) $(n=42)$. All patients provided written informed consent and received NA therapy for up to 96 weeks. The trial has been approved by the Institutional Review Board of Nanfang Hospital, Southern Medical University (ID: ZHF2011206), and described in detail previously (Cai et al., 2016, 2018). In addition, patients who did not have stored serum samples at week 0,12 , and 24 during the follow-up treatment, were excluded from this study. Treatment response was determined after 1-year (week 48) and 2-year (week 96) treatment. A virological response (VR) was defined as HBV DNA levels $<300$ copies/mL.

\section{Serological Methods}

Serum HBsAg, HBeAg, HBeAb levels were measured by the ARCHITECT i2000SR system (Abbott Laboratories, United States). Serum HBV DNA levels were measured by the Cobas Ampliprep and Cobas TaqMan, version 2.0 (CAP/CTM, Switzerland), with a detection limit ranging from 20 to $1.7 \times 10^{8} \mathrm{IU} / \mathrm{mL}(1 \mathrm{IU} / \mathrm{mL}=5.82$ copies $/ \mathrm{mL})$.

\section{MicroRNA Isolation and Quantitative Real-Time PCR}

The isolation of serum miRNA-122 was performed by the miRNeay Serum/Plasma Kit (QIAGEN, Germany) according to the manufacturer's instructions and Caenorhabditis elegans miR-39 was used to act as an internal control. The cDNA was synthesized by miScript Reverse Transcription Kit (QIAGEN) and quantification of miRNA was performed with miScript SYBR Green PCR Kit (QIAGEN) by using LightCycler 480 (Roche Diagnostics, Switzerland). The results were normalized against $10^{6}$ copies of $C$. elegans miR-39 miRNA transcripts, same as our previous study (Ge et al., 2017), and presented as the $\log _{10}$ normalized value for appropriate display, shown as $\lg$ miR-122/10 6 miR-39 copies.

\section{Statistical Analysis}

Continuous variables were shown as mean \pm SD or median as appropriate. Differences between two groups were analyzed by Mann-Whitney $U$-test and Chi-squared test, when applicable. Dynamic changes in serum miR-122 level were evaluated by repeated measures analysis. Receiver operating characteristic (ROC) curves were used to determine the accuracy of using serum miR-122 levels to predict treatment response to NA therapy. All of the statistical analyses were performed with SPSS Statistics 24.0 and GraphPad Prism 7.0. $P$-values of $<0.05$ were considered statistically significant.

\section{RESULTS}

\section{Patient Characteristics}

Baseline characteristics of all patients enrolled in this study are shown in Table 1. All patients were HBeAg-positive. At week 48 and $96,41 \%(33 / 80)$, and $84 \%(67 / 80)$ patients achieved virological response, respectively. The pre-treatment serum miR122 levels in patients treated with combination therapy (LAM $+\mathrm{ADV})$ and ETV monotherapy were $84364 \pm 123355 / 10^{6}$ miR-39 copies and $119081 \pm 367141 / 10^{6}$ miR-39 copies, respectively. There were no significant differences between the two groups in distribution of both demographics and clinical characteristics at baseline. 
TABLE 1 | Patient characteristics.

\begin{tabular}{|c|c|c|c|c|}
\hline & & LAM+ADV group $(n=38)$ & ETV group $(n=42)$ & $p$-value \\
\hline Age (years) & & $29.9 \pm 8.5$ & $29.9 \pm 8.1$ & 0.912 \\
\hline Gender, male (\%) & & $28(73.7)$ & 33 (78.6) & 0.608 \\
\hline $\operatorname{ALT}(U / L)$ & & $229.5 \pm 137.0$ & $246.3 \pm 162.7$ & 0.877 \\
\hline HBV DNA $\left(\log _{10} 1 \mathrm{U} / \mathrm{mL}\right)$ & & $7.95 \pm 0.57$ & $7.99 \pm 0.69$ & 0.345 \\
\hline miR-122/10 6 miR-39 copies & & $84364 \pm 123355$ & $119081 \pm 367141$ & 0.977 \\
\hline \multirow[t]{2}{*}{ Virological response } & week 48 & $14(36.8)$ & $19(45.2)$ & 0.446 \\
\hline & week 96 & 33 (86.8) & $34(81.0)$ & 0.476 \\
\hline
\end{tabular}

Continuous variables are shown as mean $\pm S D$, categorical variables as $n$ (\%).

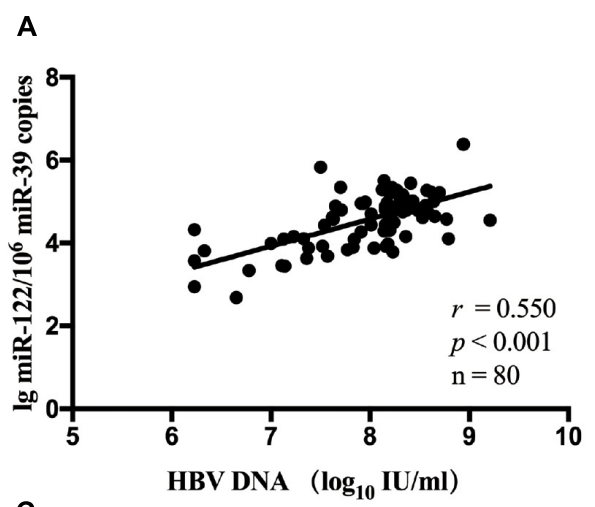

C

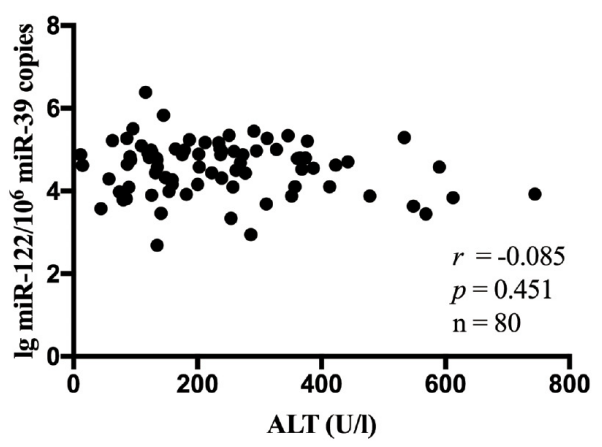

B
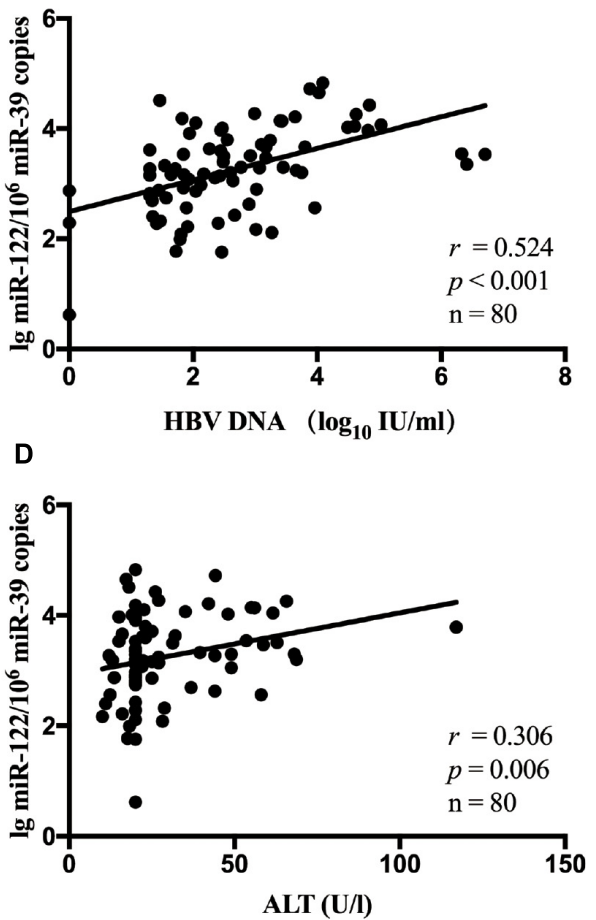

FIGURE 1 | The correlation between serum miR-122 levels, viral loads and ALT levels in all patients. Spearman's correlations of serum miR-122 levels and HBV DNA levels were conducted at baseline (A) and week 24 (B). Spearman's correlations of serum miR-122 levels and ALT levels were conducted at baseline (C) and week 24 (D).

\section{Serum miR-122 Levels Positively Associated With Serum HBV DNA Levels in CHB Patients}

It has been estimated that miR-122 played a role in chronic HBV infection. Hence, in all patients, the association between serum miR-122 levels, viral loads and ALT levels was evaluated. A significant correlation between miR-122 levels and viral loads was observed at baseline $(r=0.550$, $p<0.001$, Figure 1A) and week $24(r=0.524, p<0.001$, Figure 1B), using spearman analysis. However, no correlation was found between miR-122 levels and ALT levels at baseline $(r=-0.085, p=0.451$, Figure 1C), whereas at week 24, a significant correlation was observed $(r=0.306$, $p=0.006$, Figure 1D).

\section{Serum miR-122 Levels Discriminated Different Patient Groups of Treatment Response}

A total of 80 patients were divided into two groups according to whether they achieved a VR after 96-week NA treatment. As shown in Figure 2A, patients with a VR at week 96 showed significantly lower serum miR-122 levels at week $12(p<0.001)$ and $24(p=0.001)$ than those without a VR at week 96. Yet, these two subgroups showed approximate levels of miR122 at baseline. Given the results and the positive correlation between miR-122 and viral loads, higher miR-122 levels in serum after 12 to 24-week NA therapy might indicate the suboptimal treatment response and impediment to cure. Similar results were observed among patients with or without a VR at week 48. At 

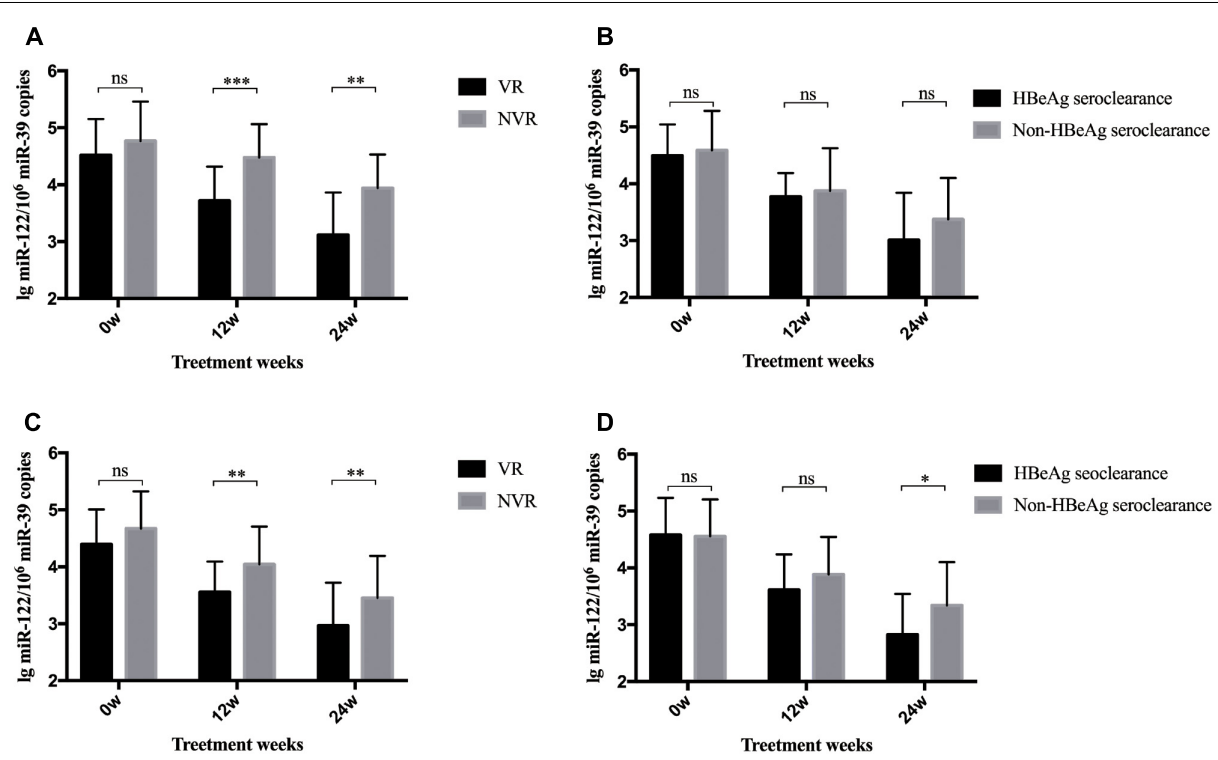

FIGURE 2 | Differential levels of serum miR-122 among subgroups. The bars represent the mean and standard error of mean. (A) MiR-122 levels in serum at baseline, week 12, and week 24 among patient groups whether a VR was achieved at week 96. (B) MiR-122 levels at baseline, week 12 , and week 24 among patient groups whether HBeAg clearance was achieved at week 96. (C) MiR-122 levels in serum at baseline, week 12, and week 24 among patient groups whether a VR was achieved at week 48. (D) MiR-122 levels at baseline, week 12, and week 24 among patient groups whether HBeAg clearance was achieved at week 48. VR, virological response; NVR, non-virological response; ns, not significant; ${ }^{*} p<0.05 ;{ }^{* *} p<0.01 ;{ }^{* * *} p<0.001$.

baseline, patients in VR and non-virological response (NVR) showed approximate miR-122 levels, whereas at week 12 and 24, significantly lower miR-122 levels were observed in VR group ( $p=0.002$ and $p=0.006$, respectively) (Figure 2C). Furthermore, patients with HBeAg seroclearance at week 48 showed lower serum miR-122 levels than those with sustained positive $\mathrm{HBeAg}$ $(p<0.001)$ (Figure 2D), regretfully, similar differential level was not found between patients whether HBeAg seroclearance was developed at week 96 (Figure 2B).

\section{The Predictive Value of Serum miR-122 Levels for Virological Response in CHB Patients Treated With NAs}

Univariate and multivariate analyses were performed to identify the associations between serum miR-122 levels and
VR at week 96. In univariate analysis, miR-122 levels at week 12 and 24 were significantly associated with a VR at week 96 ( $p=0.001$ and $p=0.001$, respectively) (Table 2), increased the possibility of VR and served as protective factors in antiviral process. Similar results were revealed in multivariate analysis, indicating miR-122 levels as independent prognostic indicator. Furthermore, to evaluate the predictive value of serum miR-122 levels for VR in $\mathrm{CHB}$ patients treated with NAs, the ROC curve was generated. The optimal cutoff value for miR-122 levels in serum at week 12 and 24 were $24075.73 / 10^{6} \mathrm{miR}-39$ copies and 4892.80/10 $\mathrm{miR}-39$ copies, respectively. The sensitivity of miR-122 levels at week 12 for prediction of a VR at week 96 was $88.1 \%$ with a specificity of $61.5 \%$, the sensitivity of miR-122 levels at week 24 was $80.6 \%$ with a specificity of $69.2 \%$ (Figure 3). The results suggested that lower miR-122 level in serum at

TABLE 2 | Univariate and multivariate analyses of associations between miR-122 levels and virological response at week 96.

\begin{tabular}{|c|c|c|c|c|c|c|}
\hline \multirow[t]{2}{*}{ Variables } & \multicolumn{3}{|c|}{ Univariate analysis } & \multicolumn{3}{|c|}{ Multivariate analysis } \\
\hline & OR & $95 \% \mathrm{Cl}$ & $p$-values & OR & $95 \% \mathrm{Cl}$ & $p$-values \\
\hline miR-122 level at baseline & 0.530 & $0.196-1.436$ & 0.212 & & & \\
\hline miR-122 level at week 12 & 0.132 & $0.041-0.421$ & 0.001 & 0.217 & $0.058-0.820$ & 0.024 \\
\hline miR-122 level at week 24 & 0.139 & $0.042-0.462$ & 0.001 & 0.278 & $0.079-0.983$ & 0.047 \\
\hline Age & 1.013 & $0.940-1.092$ & 0.734 & & & \\
\hline Gender & 1.870 & $0.376-9.299$ & 0.444 & & & \\
\hline ALT at baseline & 1.005 & $0.999-1.010$ & 0.079 & & & \\
\hline HBV DNA at baseline & 0.264 & $0.065-1.062$ & 0.061 & & & \\
\hline
\end{tabular}

VR, virological response; NVR, non-virological response. P-value $<0.05$ is shown in bold and italics. 


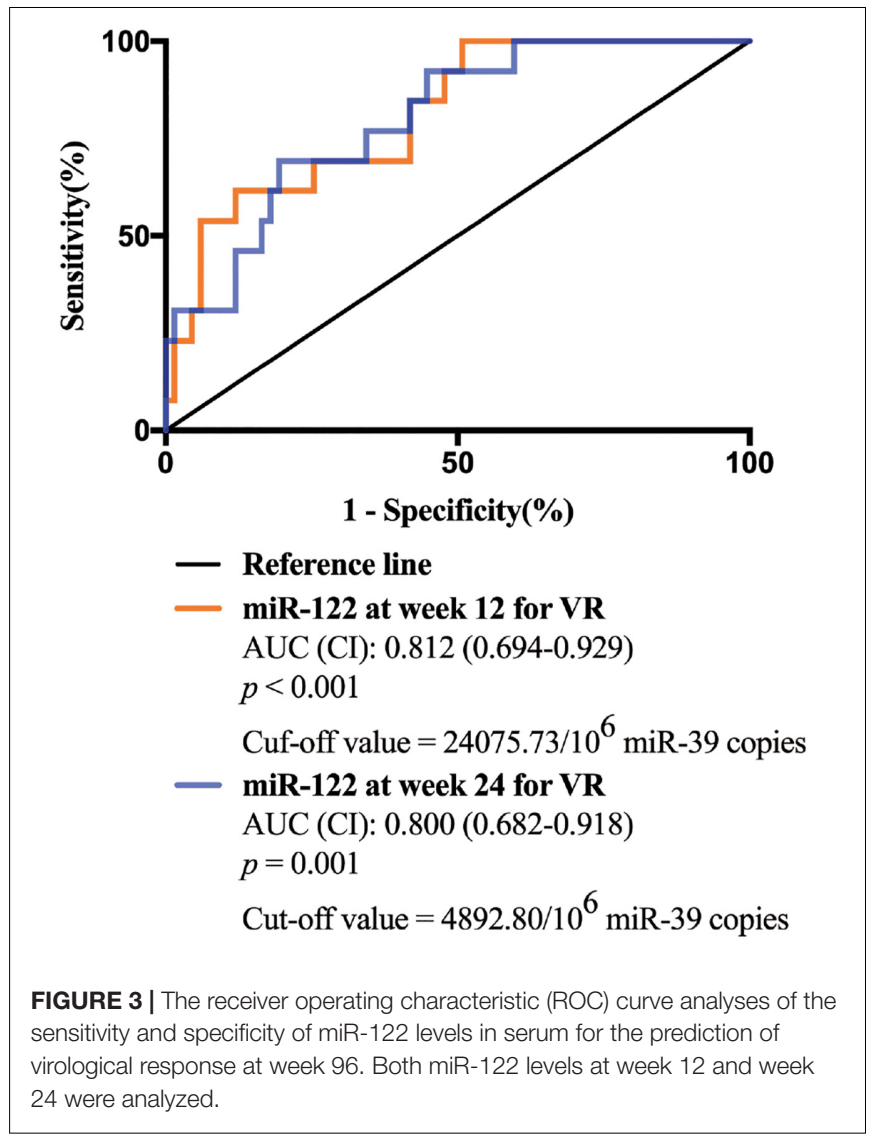

week 12 and 24 might contribute to the immune control and indicate better clinical outcomes in $\mathrm{CHB}$ patients treated with NAs.

\section{Dynamic Change of miR-122 Level During NA Therapy}

We further performed repeated measures analysis to determine the dynamic change of serum miR-122 level during NA therapy. Compared with miR-122 levels at baseline, all patients demonstrated a significant reduction of miR-122 level at week $24(p<0.001)$ (Figure 4A). VR patients showed a consistent reduction of miR-122 at both week $12(p<0.001)$ and week $24(p<0.001)$ (Figure 4B), whereas NVR patients displayed a downward but not significant trend at week $12(p=0.092)$ and significant reduction only at week $24(p=0.001)$ (Figure 4C). Reduction of miR-122 level at week 24 was observed to be significantly associated with reduction of viral load $(p<0.001)$ (Figure 4D), whereas no significant correlation was found between reduction of miR-122 and reduction of ALT levels at week 24 (Figure 4E).

\section{DISCUSSION}

In this study, we investigated the differential level of miR122 in $\mathrm{CHB}$ patients with different clinical outcomes and the dynamic change of miR-122 level in serum during NA treatment. We found that serum miR-122 levels steadily decreased during

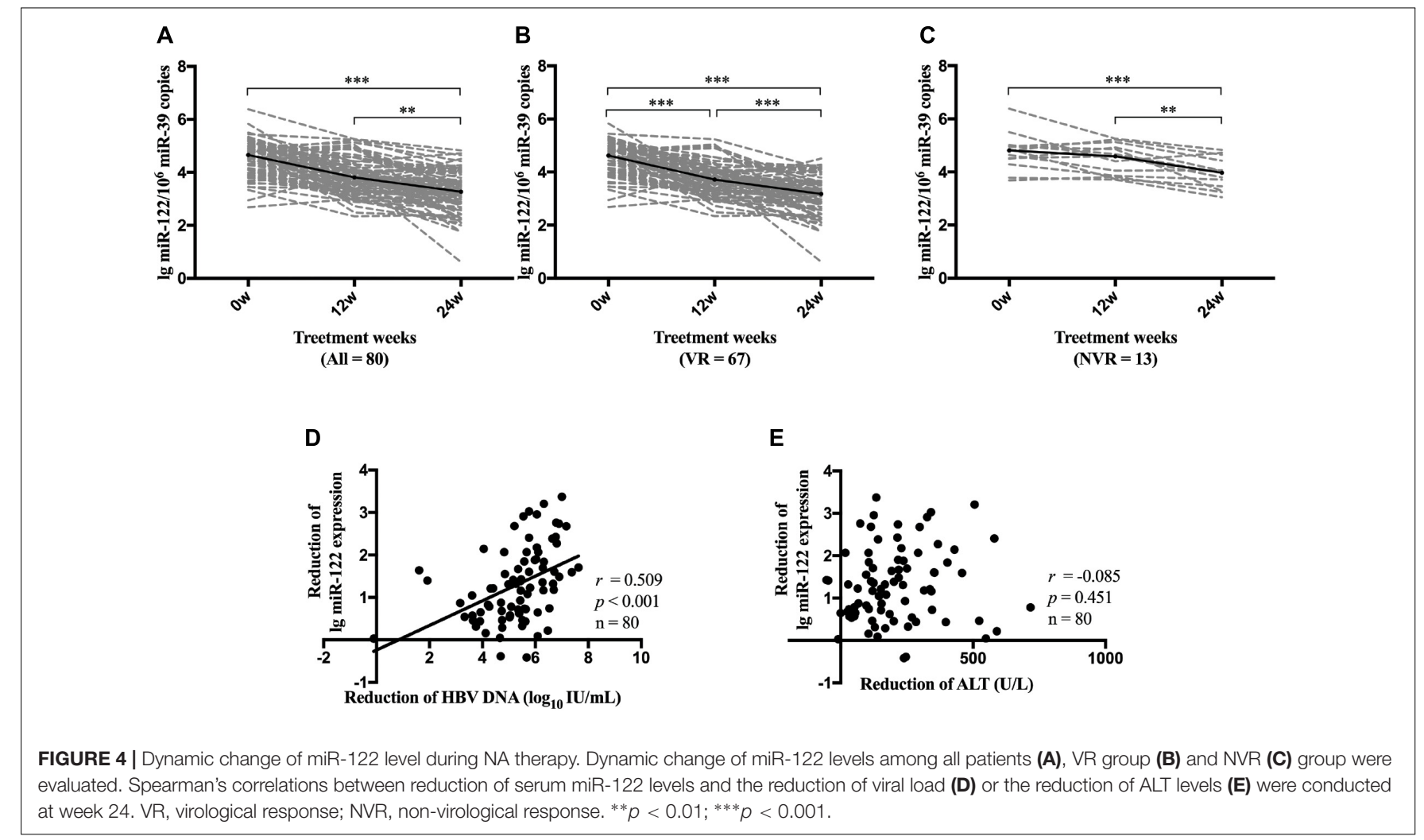


antiviral therapy and higher level of miR-122 was associated with suboptimal treatment response. Serum miR-122 level at week 12 and week 24 were identified to be satisfactory predictors for a VR at week 96.

MiR-122 has been recently studied increasingly to identify its role in hepatotropic virus infection. It has been demonstrated that miR-122 level in hepatocytes is down-regulated in $\mathrm{CHB}$ patients, and suppressed miR-122 can contribute to viral persistence through modulating inactivation of IFN expression and cyclin G(1)-modulated p53 activity (Wang et al., 2012; Gao et al., 2015), indicating this liver-specific miRNA closely involved in host-mediated antiviral defense. Given the complex methods of detecting miR-122 in liver, circulating miR-122 level displays its potential as a specific biomarker. In HBV-infected patients without any antiviral therapy, lower serum miR-122 levels exhibited a higher spontaneous HBsAg seroclearance rate (Akuta et al., 2018).

Therefore, in this study, we aimed to identify the predictive value of serum miR-122 levels and the dynamic change of miR122 level during NA therapy in $\mathrm{CHB}$ patients. In agreement with previous studies (Waidmann et al., 2012; Xing et al., 2014; Akamatsu et al., 2015), a significant and positive correlation between serum miR-122 level and viral loads was observed. However, serum miR-122 levels showed no association with ALT levels at baseline, which may be on account of the special patient cohort this study performed in. All patients enrolled in this study were with HVL of HBV DNA $>10^{7}$ copies/mL at baseline. A weak $\mathrm{T}$ cell response is often exhibited in $\mathrm{CHB}$ patients, with depletion of T cells and diminished cytotoxic capacity (Cho et al., 2017). This phenomenon which is called as $\mathrm{T}$ cell exhaustion, leads to persistence of chronic $\mathrm{HBV}$ infection and reduction of liver damage (Chang and Lewin, 2007). Serum ALT activity, known as an essential biomarker signaling liver damage, might be limited in $\mathrm{CHB}$ patients with HVL at baseline. These results indicated that miR-122 is related to viral replication rather than liver damage. Moreover, we observed significantly lower serum miR-122 levels at week 12 and week 24 in patients who developed VR at week 96 compared to non-responders. Circulating miR-122 levels at both week 12 and week 24 displayed independent prognostic value for a VR to NA therapy. In addition, we demonstrated that AUROC values for serum miR-122 were satisfactory at 0.812 and 0.800 , a miR-122 level of $<24075.73 / 10^{6}$ miR-39 copies at week 12 and $4892.80 / 10^{6}$ miR-39 copies at week 24 may be applied practically in clinical practice.

We further identified the dynamic change of miR-122 level in serum during NA therapy, which remains unknown to date. During antiviral therapy, serum miR-122 level steadily decreased and displayed a significant reduction at week 24 , while in patients who developed VR, miR-122 level decreased more rapidly with a significant reduction at week 12. However, further studies were needed to confirm whether prominent reduction of miR122 level at early phase will contribute to satisfactory treatment response. In addition, lower serum miR-122 level was observed in patients who developed HBeAg seroclearance at week 48. However, up to week 96, similar results were not observed. One possible explanation was the relatively small sample size. Further studies with larger sample size are necessary to determine the role of miR-122 in facilitating HBV clearance, promoting $\mathrm{HBeAg}$ seroclearance and even in assisting immune control after NA cessation.

This study had several limitations. One of the limitations was the absence of the contrast between $\mathrm{CHB}$ patients and healthy controls. The other was the lack of liver specimens. As only a few patients accepted liver biopsies, we did not measure the miR-122 expression in liver. Yet, it has been found that, compared with healthy controls, miR-122 expression in liver was significantly down-regulated in CHB patients (Wang et al., 2012), whereas serum miR-122 level was significantly increased (Waidmann et al., 2012; Xing et al., 2014). Thus, we speculated that there might be a negative correlation between miR-122 level in liver and in circulating system of $\mathrm{CHB}$ patients due to two possible explanations. One is that liver injury induces the secretion of extracellular vesicles containing exosomeassociated miRNAs including miR-122 into the bloodstream (Momen-Heravi et al., 2015). The other is that subviral HBsAg particles carry hepatocellular miRNAs (including miR-122) from hepatocytes to bloodstream (Novellino et al., 2012). Both of them lead to transportation of miR-122 from liver to circulating system. The speculation requires further studies to identify. Yet this is the first study to investigate the dynamic change of miR122 during antiviral therapy, and the first study to identify the prognostic value of miR-122 in non-neoplastic and non-fibrotic $\mathrm{CHB}$ patients for treatment response to NA therapy.

In conclusion, we identified the dynamic change of miR-122 levels in serum during NA therapy. Moreover, in CHB patients with HVL treated with NAs, we demonstrated that serum miR122 levels at week 12 and week 24 could provide practical application of predicting virological response.

\section{AUTHOR CONTRIBUTIONS}

JP conceived and designed the research. SC and GL collected the samples. YW, CG, and MX performed the experiments. YW analyzed the data and drafted the manuscript with additional input and suggestions from XZ. All authors reviewed and approved the manuscript.

\section{FUNDING}

This work was supported by grants from the National Natural Science Foundation of China (Grant No. 81572000) and the Clinical Research Program of Southern Medical University by High-level University Construction Funding of Guangdong Provincial Department of Education (LC2016PY003).

\section{ACKNOWLEDGMENTS}

We are grateful to all the patients in this study, the nurses who assisted in the patient management and the collection of blood samples and the kind help of Dr. Jun Ge for providing the experimental protocol. 


\section{REFERENCES}

Akamatsu, S., Hayes, C. N., Tsuge, M., Miki, D., Akiyama, R., Abe, H., et al. (2015). Differences in serum microRNA profiles in hepatitis B and $\mathrm{C}$ virus infection. J. Infect. 70, 273-287. doi: 10.1016/j.jinf.2014.10.017

Akuta, N., Suzuki, F., Kobayashi, M., Hosaka, T., Fujiyama, S., Kawamura, Y., et al. (2018). Circulating microRNA-122 levels are important predictor of hepatitis B virus surface antigen seroclearance. J. Med. Virol. 90, 1586-1592. doi: 10.1002/ jmv. 25238

Cai, S., Li, Z., Yu, T., Xia, M., and Peng, J. (2018). Serum hepatitis B core antibody levels predict $\mathrm{HBeAg}$ seroconversion in chronic hepatitis B patients with high viral load treated with nucleos(t)ide analogs. Infect. Drug Resist. 11, 469-477. doi: 10.2147/IDR.S163038

Cai, S., Yu, T., Jiang, Y., Zhang, Y., Lv, F., and Peng, J. (2016). Comparison of entecavir monotherapy and de novo lamivudine and adefovir combination therapy in $\mathrm{HBeAg}$-positive chronic hepatitis B with high viral load: 48-week result. Clin. Exp. Med. 16, 429-436. doi: 10.1007/s10238-015-0373-2

Chang, J. J., and Lewin, S. R. (2007). Immunopathogenesis of hepatitis B virus infection. Immunol. Cell Biol. 85, 16-23. doi: 10.1038/sj.icb.7100009

Chen, C.-H., Chiu, Y.-C., Lu, S.-N., Lee, C.-M., Wang, J.-H., Hu, T.-H., et al. (2014). Serum hepatitis B surface antigen levels predict treatment response to nucleos(t)ide analogues. World J. Gastroenterol. 20, 7686-7695. doi: 10.3748/ wjg.v20.i24.7686

Cho, H., Kang, H., Lee, H. H., and Kim, C. W. (2017). Programmed cell death 1 (PD-1) and cytotoxic T lymphocyte-associated antigen 4 (CTLA-4) in viral hepatitis. Int. J. Mol. Sci. 18:E1517. doi: 10.3390/ijms18071517

Dandri, M., and Locarnini, S. (2012). New insight in the pathobiology of hepatitis B virus infection. Gut 61(Suppl. 1), i6-i17. doi: 10.1136/gutjnl-2012-302056

Deng, W., and Lu, M. (2016). The role of microRNAs in hepatocyte metabolism and hepatitis B virus replication. Virol. Sin. 31, 472-479. doi: 10.1007/s12250016-3924-0

Fan, R., Sun, J., Yuan, Q., Xie, Q., Bai, X., Ning, Q., et al. (2016). Baseline quantitative hepatitis $\mathrm{B}$ core antibody titre alone strongly predicts $\mathrm{HBeAg}$ seroconversion across chronic hepatitis $\mathrm{B}$ patients treated with peginterferon or nucleos(t)ide analogues. Gut 65, 313-320. doi: 10.1136/gutjnl-2014-308546

Gao, D., Zhai, A., Qian, J., Li, A., Li, Y., Song, W., et al. (2015). Down-regulation of suppressor of cytokine signaling 3 by miR-122 enhances interferon-mediated suppression of hepatitis B virus. Antiviral Res. 118, 20-28. doi: 10.1016/j. antiviral.2015.03.001

Ge, J., Huang, Z., Liu, H., Chen, J., Xie, Z., Chen, Z., et al. (2017). Lower expression of MicroRNA-155 contributes to dysfunction of natural killer cells in patients with chronic hepatitis B. Front. Immunol. 8:1173. doi: 10.3389/fimmu.2017. 01173

Hammond, S. M. (2015). An overview of microRNAs. Adv. Drug Deliv. Rev. 87, 3-14. doi: 10.1016/j.addr.2015.05.001

Hu, J., Xu, Y., Hao, J., Wang, S., Li, C., and Meng, S. (2012). MiR-122 in hepatic function and liver diseases. Protein Cell 3, 364-371. doi: 10.1007/s13238-0122036-3

Huang, J. Y., Chen, H. L., and Shih, C. (2016). MicroRNA miR-204 and miR1236 inhibit hepatitis B virus replication via two different mechanisms. Sci. Rep. 6:34740. doi: 10.1038/srep34740

Jaroszewicz, J., Ho, H., Markova, A., Deterding, K., Wursthorn, K., Schulz, S., et al. (2011). Hepatitis B surface antigen (HBsAg) decrease and serum interferoninducible protein-10 levels as predictive markers for HBsAg loss during treatment with nucleoside/nucleotide analogues. Antivir. Ther. 16, 915-924. doi: 10.3851/IMP1866

Lagos-Quintana, M., Rauhut, R., Yalcin, A., Meyer, J., Lendeckel, W., and Tuschl, T. (2002). Identification of tissue-specific microRNAs from mouse. Curr. Biol. 12, 735-739. doi: 10.1016/S0960-9822(02)00809-6

Lampertico, P., Agarwal, K., Berg, T., Buti, M., Janssen, H. L. A., Papatheodoridis, G., et al. (2017). EASL 2017 clinical practice guidelines on the management of hepatitis B virus infection. J. Hepatol. 67, 370-398. doi: 10.1016/j.jhep.2017.03.021
Landgraf, P., Rusu, M., Sheridan, R., Sewer, A., Iovino, N., Aravin, A., et al. (2007). A mammalian microRNA expression atlas based on small RNA library sequencing. Cell 129, 1401-1414. doi: 10.1016/j.cell.2007.04.040

Momen-Heravi, F., Saha, B., Kodys, K., Catalano, D., Satishchandran, A., and Szabo, G. (2015). Increased number of circulating exosomes and their microRNA cargos are potential novel biomarkers in alcoholic hepatitis. J. Transl. Med. 13:261. doi: 10.1186/s12967-015-0623-9

Novellino, L., Rossi, R. L., Bonino, F., Cavallone, D., Abrignani, S., Pagani, M., et al. (2012). Circulating hepatitis B surface antigen particles carry hepatocellular microRNAs. PLoS One 7:e31952. doi: 10.1371/journal.pone.003 1952

Perrillo, R. P., Lai, C. L., Liaw, Y. F., Dienstag, J. L., Schiff, E. R., Schalm, S. W., et al. (2002). Predictors of $\mathrm{HBeAg}$ loss after lamivudine treatment for chronic hepatitis B. Hepatology 36, 186-194. doi: 10.1053/jhep.2002.34294

Potenza, N., Papa, U., Mosca, N., Zerbini, F., Nobile, V., and Russo, A. (2011). Human microRNA hsa-miR-125a-5p interferes with expression of hepatitis B virus surface antigen. Nucleic Acids Res. 39, 5157-5163. doi: 10.1093/nar/gkr067

Schweitzer, A., Horn, J., Mikolajczyk, R. T., Krause, G., and Ott, J. J. (2015). Estimations of worldwide prevalence of chronic hepatitis B virus infection: a systematic review of data published between 1965 and 2013. Lancet 386, 1546-1555. doi: 10.1016/S0140-6736(15)61412-X

Waidmann, O., Bihrer, V., Pleli, T., Farnik, H., Berger, A., Zeuzem, S., et al. (2012). Serum microRNA-122 levels in different groups of patients with chronic hepatitis B virus infection. J. Viral Hepat. 19, e58-e65. doi: 10.1111/j.1365-2893. 2011.01536.x

Wang, C. C., Tseng, T. C., Wang, P. C., Lin, H. H., and Kao, J. H. (2014) Baseline hepatitis $\mathrm{B}$ surface antigen quantitation can predict virologic response in entecavir-treated chronic hepatitis B patients. J. Formos. Med. Assoc. 113, 786-793. doi: 10.1016/j.jfma.2013.06.003

Wang, S., Qiu, L., Yan, X., Jin, W., Wang, Y., Chen, L., et al. (2012). Loss of microRNA 122 expression in patients with hepatitis B enhances hepatitis B virus replication through cyclin G(1) -modulated P53 activity. Hepatology 55, 730-741. doi: 10.1002/hep.24809

Wong, D., Littlejohn, M., Edwards, R., Jackson, K., Revill, P., Gaggar, A., et al. (2018). ALT flares during nucleotide analogue therapy are associated with HBsAg loss in genotype A HBeAg-positive chronic hepatitis B. Liver Int. 38, 1760-1769. doi: 10.1111/liv.13716

Wong, G. L., Chan, H. L., Chan, H. Y., Tse, C. H., Chim, A. M., Lo, A. O., et al. (2016). Serum interferon-inducible protein 10 levels predict hepatitis B s antigen seroclearance in patients with chronic hepatitis B. Aliment. Pharmacol. Ther. 43, 145-153. doi: 10.1111/apt.13447

Xing, T. J., Jiang, D. F., Huang, J. X., and Xu, Z. L. (2014). Expression and clinical significance of miR-122 and miR-29 in hepatitis B virus-related liver disease. Genet. Mol. Res. 13, 7912-7918. doi: 10.4238/2014.September.29.4

Zhang, G. L., Li, Y. X., Zheng, S. Q., Liu, M., Li, X., and Tang, H. (2010). Suppression of hepatitis B virus replication by microRNA-199a-3p and microRNA-210. Antiviral Res. 88, 169-175. doi: 10.1016/j.antiviral.2010. 08.008

Zhao, F., Xu, G., Zhou, Y., Wang, L., Xie, J., Ren, S., et al. (2014). MicroRNA26b inhibits hepatitis B virus transcription and replication by targeting the host factor CHORDC1 protein. J. Biol. Chem. 289, 35029-35041. doi: 10.1074/jbc. M114.589978

Conflict of Interest Statement: The authors declare that the research was conducted in the absence of any commercial or financial relationships that could be construed as a potential conflict of interest.

Copyright (C) 2019 Wu, Gao, Cai, Xia, Liao, Zhang and Peng. This is an open-access article distributed under the terms of the Creative Commons Attribution License (CC BY). The use, distribution or reproduction in other forums is permitted, provided the original author(s) and the copyright owner(s) are credited and that the original publication in this journal is cited, in accordance with accepted academic practice. No use, distribution or reproduction is permitted which does not comply with these terms. 